\title{
Sch 1385568, a new azaphilone from Aspergillus sp.
}

\author{
Shu-Wei Yang, Tze-Ming Chan, Joseph Terracciano ${ }^{1}$, David Loebenberg, Mahesh Patel ${ }^{2}$, Vincent Gullo ${ }^{3}$ \\ and Min $\mathrm{Chu}^{1}$
}

The Journal of Antibiotics (2009) 62, 401-403; doi:10.1038/ja.2009.51; published online 26 June 2009

Keywords: Aspergillus sp.; azaphilone; Sch 1385568; structure elucidation

In the course of our continuing search for novel antimicrobial agents, ${ }^{1,2}$ we have identified a novel azaphilone Sch 1385568 (1) (Scheme 1) from an Aspergillus sp. culture (SPRI-0814). Various azaphilones and hydrogenated azaphilones have been isolated mainly from fungal species, such as Emericella sp., ${ }^{3-5}$ Penicillium sp., ${ }^{6-8}$ Phomopsis sp., ${ }^{9}$ Chaetomium sp. ${ }^{10}$ Pseudohalonectria sp. ${ }^{11}$ and Anuulohypoxylon sp. ${ }^{12}$ Some of them have been described to show biological activities against various targets related to the different therapeutic areas, including cardiovascular, lipid metabolism, inflammatory, antiinfectious and antitumor areas. More specifically, azaphilones have been reported to display inhibitory activity against the following targets: acyl-CoA: cholesterol acyltransferase, ${ }^{6}$ endothelin receptor, ${ }^{8}$ cholesteryl ester transfer protein, ${ }^{13}$ platelet-derived growth factor, ${ }^{14}$ gp120-CD $4,{ }^{15}$ monoamine oxidase, ${ }^{16}$ phospholipase $\mathrm{A}_{2}{ }^{17}$ and nitric oxide production. ${ }^{18}$ Some azaphilones have also been reported to display antitumor ${ }^{10,19}$ and antimicrobial activities. ${ }^{10-12}$ In this communication, we describe the fermentation, isolation, structure elucidation and antimicrobial activity of $\mathbf{1}$.

Fermentation of Aspergillus sp. culture SPRI-0814 was conducted in shake flasks. Stock cultures were maintained as frozen whole broths at $-80^{\circ} \mathrm{C}$ in a final concentration of $10 \%$ glycerol. The germination medium contained proteus peptone $5.0 \mathrm{~g}, \mathrm{NaCl} 5.0 \mathrm{~g}, \mathrm{KH}_{2} \mathrm{PO}_{4} 5.0 \mathrm{~g}$, yeast extract $3.0 \mathrm{~g}$, cerelose $20 \mathrm{~g}$ and soybean grits $5.0 \mathrm{~g}$ in $1.01 \mathrm{lap}$ water with $\mathrm{pH} 7.0$ before autoclaving. Each $250 \mathrm{ml}$ flask containing $70 \mathrm{ml}$ of this medium was inoculated with $2 \mathrm{ml}$ of the stock culture. The flasks were incubated at $24^{\circ} \mathrm{C}$ on a rotary shaker at $250 \mathrm{rpm}$ for 4 days to obtain the first stage seed. The above procedure was repeated using the first stage seed to obtain the second stage seed. This second stage seed was then used to inoculate the fermentation medium at $5 \%$ $\mathrm{v} / \mathrm{v}$. The fermentation was carried out in $500 \mathrm{ml}$ flasks, each containing $100 \mathrm{ml}$ of the fermentation medium, which consisted of neopeptone $10 \mathrm{~g}$ and cerelose $40 \mathrm{~g}$ in $1.0 \mathrm{l}$ tap water. The $\mathrm{pH}$ was adjusted to 7.4, and $\mathrm{CaCO}_{3}\left(4 \mathrm{gl}^{-1}\right)$ was added. The flasks were incubated at $24^{\circ} \mathrm{C}$ in a rotary shaker at $250 \mathrm{rpm}$ for 7 days.
The harvested fermentation broth (10 l) was mixed with $\mathrm{NaCl}(2 \mathrm{~kg})$ and acetonitrile $(\mathrm{MeCN}, 20 \mathrm{l})$ for $15 \mathrm{~min}$. The organic layer was separated and concentrated to a slurry, and then the slurry material was absorbed onto the polymeric resin, CG161 ( $\sim 200 \mathrm{ml}$, Tosoh Biosep LLC, Montgomeryville, PA, USA). The salts and hydrophilic substances were removed by washing with water (201). Then, the absorbed organic material was eluted with $85 \%$ aq. $\mathrm{MeOH}(4 \mathrm{l})$ to yield $\sim 2.4 \mathrm{~g}$ of dried material after concentration in vacuo. Part of this organic material was purified on a semi-preparative ODS-A HPLC column (YMC, $120 \AA$, S-7, 20×250 mm; Waters HPLC, Millennium System (Milford, MA, USA), equipped with a photodiode array detector). The column was eluted with a gradient of $\mathrm{MeCN}-\mathrm{H}_{2} \mathrm{O}$ : $5-100 \% \mathrm{MeCN}$ in $50 \mathrm{~min}$, and then held isocratically with $100 \%$ $\mathrm{MeCN}$ for an additional $15 \mathrm{~min}$ with a flow rate of $15 \mathrm{ml} \mathrm{min}^{-1}$. All fractions were collected and analyzed on the basis of a UV chromatogram. Pure 1 ( $\sim 5 \mathrm{mg})$ was obtained from three injections of the enriched material (40 $\mathrm{mg}$ each).

The structure of $\mathbf{1}$ was mainly elucidated by extensive one- and two-dimensional NMR analyses. In the ${ }^{1} \mathrm{H}-\mathrm{NMR}$ spectrum, a total of 17 carbon-attached protons were detected. Three methyl and one methine signals were observed in the aliphatic region, and eight resonances were observed in the low-field region. In the ${ }^{13} \mathrm{C} N M R$ spectrum, 21 carbon signals were detected, in which a conjugated ketone functionality (C-6, $\delta$ 200.0) was identified. The molecular ion $m / z 385,[\mathrm{M}+\mathrm{H}]^{+}$was observed on an electrospray ionisation-MS instrument (Applied Biosystem, Foster City, CA, USA, API-150Ex spectrometer), and therefore the molecular formula of 1 was calculated as $\mathrm{C}_{21} \mathrm{H}_{20} \mathrm{O}_{7}$. From the analyses of NMR and MS data, three hydroxyl groups were proposed to be present in the molecule based on only 17 protons observed in the ${ }^{1} \mathrm{H}$-NMR spectrum. The azaphilone skeleton was mainly determined by ${ }^{1} \mathrm{H}-{ }^{13} \mathrm{C}$ long-range correlations measured in a heteronuclear multiple bond correlation (HMBC) experiment. The methyl group showing a doublet-doublet resonance $\left(\mathrm{H}_{3}-3^{\prime}, \delta 1.88\right.$, dd, $\left.J=7.0,1.7 \mathrm{~Hz}\right)$ in ${ }^{1} \mathrm{H}-\mathrm{NMR}$ was determined to be 


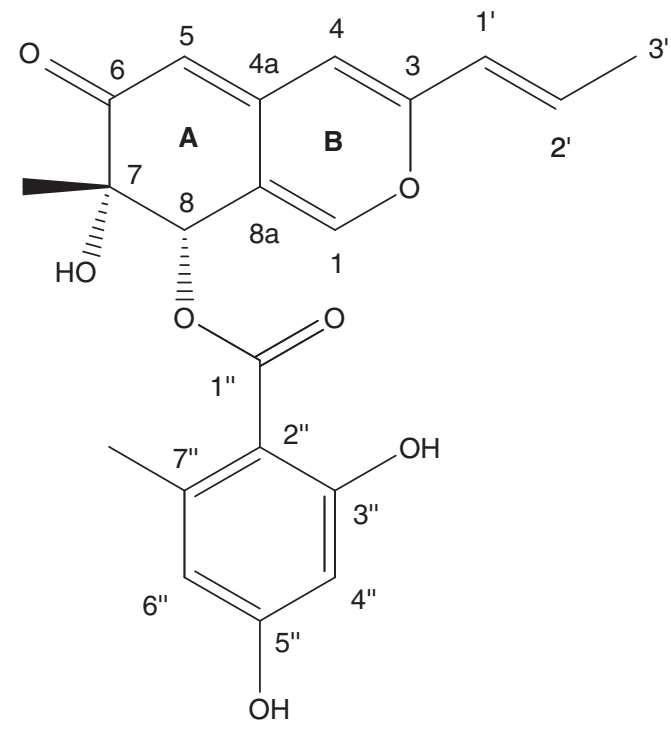

Sch1385568 (1)

Scheme 1 Structure of 1.

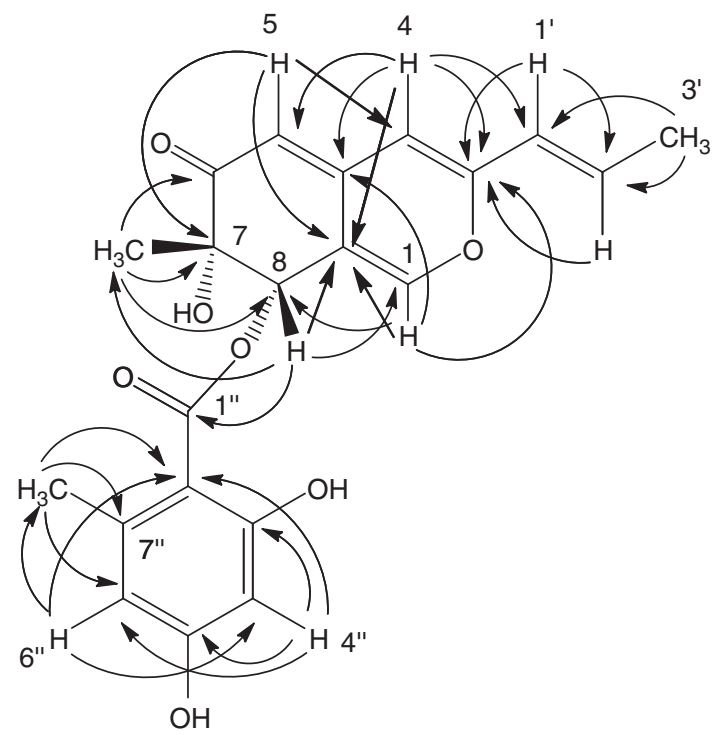

Figure 1 HMBC correlations of 1.

adjacent to a double bond consisting of two olefinic methine carbons (C-1' and C-2') because of the observation of the correlations between $\mathrm{H}_{3}-3^{\prime}$ and $\mathrm{C}-1^{\prime}\left(\delta\right.$ 124.4) and $\mathrm{C}-2^{\prime}(\delta$ 136.0). This double bond was conjugated to the additional two double bonds and further extended to the ketone (C-6) at the other end on the basis of the following correlations: $\mathrm{H}-1^{\prime}$ to $\mathrm{C}-3$; $\mathrm{H}-2^{\prime}$ to $\mathrm{C}-3$; $\mathrm{H}-4$ to C-3, C-4a, C-5, and C$1^{\prime}$; $\mathrm{H}-5$ to $\mathrm{C}-4$ and $\mathrm{C}-7$; $\mathrm{CH}_{3}-7$ to $\mathrm{C}-6$ and $\mathrm{C}-7$ (Figure 1). The NOE correlations observed between $\mathrm{H}-\mathrm{1}^{\prime}$ and $\mathrm{H}_{3}-3^{\prime}, \mathrm{H}-\mathrm{1}^{\prime}$ and $\mathrm{H}-4^{\prime}$, and $\mathrm{H}-$ 4 and H-5 established linear conjugation and regiochemistry of the ketone-tri-ene moiety. The oxygenated olefin proton signal ( $\mathrm{H}-1, \delta$ 7.75) showed correlations to the oxygenated olefinic C-3 ( $\delta$ 157.5), C$4 \mathrm{a}(\delta 146.7)$ and C-8a $(\delta 117.3)$ assembling a pyran moiety (ring B). The second methyl group $\left(7-\mathrm{CH}_{3}, \delta 1.36\right.$, s) substituted on an oxygenated quaternary carbon $(\mathrm{C}-7, \delta 75.3)$ was located adjacent to
Table 1 NMR spectral data for compound 1 in $\mathrm{CD}_{3} O \mathrm{D}^{\mathrm{a}}$

\begin{tabular}{|c|c|c|c|}
\hline $\mathrm{C} / \mathrm{H}$ no. & ${ }^{1} H(\delta)$ & ${ }^{13} \mathrm{C}(\delta)^{\mathrm{b}}$ & ${ }^{1} H_{-}{ }^{1} H \cos Y$ \\
\hline 1 & $7.75,1 \mathrm{H}, \mathrm{d}, J=1.2$ & $150.9 \mathrm{~d}$ & $\mathrm{H}-5$ \\
\hline 3 & & $157.5 \mathrm{~s}$ & \\
\hline 4 & $6.25,1 \mathrm{H}, \mathrm{s}$ & $103.9 \mathrm{~d}$ & \\
\hline $4 a$ & & $146.7 \mathrm{~s}$ & \\
\hline 5 & $5.44,1 \mathrm{H}, \mathrm{d}, J=1.2$ & $105.9 \mathrm{~d}$ & \\
\hline 6 & & $200.0 \mathrm{~s}$ & \\
\hline 7 & & $75.3 \mathrm{~s}$ & \\
\hline 7-Me & $1.36,3 \mathrm{H}, \mathrm{s}$ & $24.6 q$ & \\
\hline 8 & $5.88,1 \mathrm{H}, \mathrm{s}$ & $76.2 \mathrm{~d}$ & \\
\hline $8 a$ & & $117.3 \mathrm{~s}$ & \\
\hline $1^{\prime}$ & $6.11,1 \mathrm{H}, \mathrm{dq}, J=15.8,1.7$ & $124.4 \mathrm{~d}$ & $\mathrm{H}-2^{\prime}$ \\
\hline $2^{\prime}$ & $6.57,1 \mathrm{H}, \mathrm{dq}, J=15.8,7.0$ & $136.0 \mathrm{~d}$ & $\mathrm{H}-1^{\prime}, \mathrm{H}-3^{\prime}$ \\
\hline $3^{\prime}$ & $1.88,3 \mathrm{H}, \mathrm{dd}, J=7.0,1.7$ & $18.7 \mathrm{q}$ & $\mathrm{H}-2^{\prime}$ \\
\hline $1^{\prime \prime}$ & & $172.3 \mathrm{~s}$ & \\
\hline $2^{\prime \prime}$ & & $105.7 \mathrm{~s}$ & \\
\hline $3^{\prime \prime}$ & & $166.5 \mathrm{~s}$ & \\
\hline $4^{\prime \prime}$ & $6.11,1 \mathrm{H}, \mathrm{d}, \mathrm{J}=2.5$ & $101.8 \mathrm{~d}$ & $\mathrm{H}-6^{\prime \prime}$ \\
\hline $5^{\prime \prime}$ & & $164.3 \mathrm{~s}$ & \\
\hline $6^{\prime \prime}$ & $6.13,1 \mathrm{H}, \mathrm{d}, J=2.5$ & $112.8 \mathrm{~d}$ & $\mathrm{H}-4^{\prime \prime}$ \\
\hline $7^{\prime \prime}$ & & $145.2 \mathrm{~s}$ & \\
\hline 7"-Me & $2.25,3 \mathrm{H}, \mathrm{s}$ & $24.7 \mathrm{q}$ & \\
\hline
\end{tabular}

aRecorded on a Varian Unity 500 NMR instrument (Varian, Palo Alto, CA, USA) at $500 \mathrm{MHz}$ for ${ }^{1} \mathrm{H}$ and $125 \mathrm{MHz}$ for ${ }^{13} \mathrm{C}$, using standard Varian pulse sequence programs (VNMR Version 6.1 Software). $\delta$ in ppm; $J$ in $\mathrm{Hz}$.

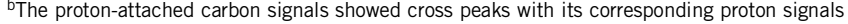
in the HSQC-COSY spectrum.

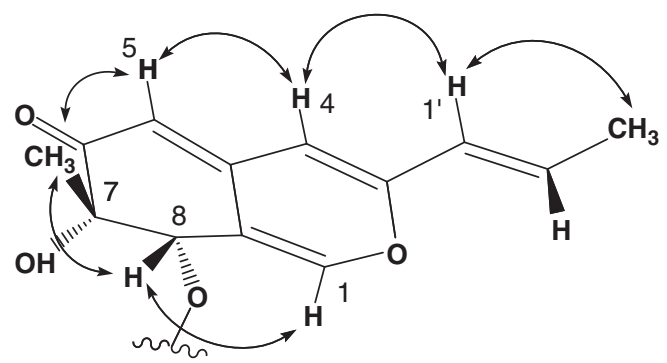

Figure 2 The relative configuration of 1 and NOE correlations observed in NOESY spectrum (represented by double arrows).

the conjugated ketone (C-6) and an aliphatic oxygenated methine carbon $(\mathrm{C}-8, \delta 76.2)$ because of the significant coupling of $\mathrm{CH}_{3}-7$ and C-7, C-6 and C-8. C-8 was further identified to connect to C-8a based on the following long-range correlations: $\mathrm{H}-8$ to $\mathrm{C}-1$ and $\mathrm{C}-8 \mathrm{a} ; \mathrm{H}-1$ to $\mathrm{C}-8$. Therefore, the six-member ring A was constructed on the basis of these evidences. Thus, the 7,8-dihydro-6H-isochromen-6-one ring skeleton was determined.

The remaining seven carbons were constructed to represent a 2,4dihydroxy-6-methyl-benzoyl moiety based on the following observation: correlations $\mathrm{H}-4^{\prime \prime}$ to $\mathrm{C}-2^{\prime \prime}, \mathrm{C}-3^{\prime \prime}, \mathrm{C}-5^{\prime \prime}$ and C-6"; $\mathrm{H}-6^{\prime \prime}$ to C-2", $\mathrm{C}-4^{\prime \prime}, \mathrm{C}-5^{\prime \prime}$ and $\mathrm{CH}_{3}-7^{\prime \prime}$; $\mathrm{CH}_{3}-7^{\prime \prime}$ to $\mathrm{C}-2^{\prime \prime}, \mathrm{C}-6^{\prime \prime}$ and $\mathrm{C}-7^{\prime \prime}$. The ${ }^{13} \mathrm{C}$ chemical shifts of the highly substituted benzoyl moiety were identical to the data of the same benzoyl moiety reported in the literature. ${ }^{20}$ The benzoyl group was unambiguously assigned to the 8-O position based on the correlation of H-8 and C-1" $(\delta$ 172.3). Thus, the twodimensional structure of 1 was determined, and the unambiguous assignment of the ${ }^{1} \mathrm{H}$ and ${ }^{13} \mathrm{C}$ chemical shifts was accomplished on the basis of the two-dimensional NMR data analyses including ${ }^{1} \mathrm{H}-{ }^{1} \mathrm{H}$ COSY, HSQC and HMBC as detailed in Table 1. 
The stereochemistry of 1 was established by the analyses of ${ }^{1} \mathrm{H}-{ }^{1} \mathrm{H}$ coupling constants and NOESY. The double bond $\Delta 1^{\prime}, 2^{\prime}$ was determined as trans because of the typical large coupling constant $(J=15.8 \mathrm{~Hz})$. The relative stereochemistry on C-7 and C-8 was assigned as cis configuration on the basis of the NOE correlations between $\mathrm{H}-8$ and $\mathrm{CH}_{3}-7$ as shown in Figure 2. The highly conjugated system and the double bond $\Delta 1,8$ a led to the flat bicyclic ring system, causing pseudoaxial orientation of the 7-methyl group, sterically close to $\mathrm{H}-8$. The absolute configuration of $\mathbf{1}$ was not studied because of the limited amount of the sample.

Most of the previously reported azaphilones possess benzoyl substitution on the C-7 position. ${ }^{3-5}$ Benzoyl substitution on C-8 for azaphilone is rare. ${ }^{6,7,21}$ To the best of our knowledge, Sch1385568 (1) represents the fourth example of a C-8 benzoyl-substituted azaphilone. It is a close analog of Sch 725680 and mitorubrinic acid B. Sch 725680 is a 1,8 a-dihydroazaphilone derivative of $\mathbf{1}^{21}$ and mitorubrinic acid $\mathrm{B}$ is an oxidative acidic analog of $\mathbf{1}$ at the $3^{\prime}$ position. ${ }^{7}$

Sch1385568 (1) was evaluated for its antimicrobial activity. It displayed antifungal activity against Saccharomyces cerevisiae $(\mathrm{PM} 503)^{22}$ with an MIC of $32 \mu \mathrm{g} \mathrm{ml}^{-1}$, and it was inactive against Candida albicans (C43) with an MIC of $256 \mu \mathrm{g} \mathrm{ml}^{-1}$. In addition, 1 did not show antibacterial activity against Staphylococcus aureus at $256 \mu \mathrm{g} \mathrm{ml}^{-1}$.

\section{ACKNOWLEDGEMENTS}

We are grateful to Mr Lewis B Fan for extract preparation and to Mr Ross Yang for MS measurement.

1 Yang, S. W. et al. A new 5-alkenylresorcinol Sch 725681 from Aspergillus sp. J. Antibiot. 59, 190-192 (2006).

2 Yang, S. W. et al. Structure elucidation of Sch 725674 from Aspergillus sp. J. Antibiot 58, 535-538 (2005)

3 Itabashi, T. et al. Falconensins A, B, C, and D, new compounds related to azaphilone, from Emericella falconensis. Chem. Pharm. Bull. 40, 3142-3144 (1992).

4 Itabashi, T., Nozawa, K., Nakajima, S. \& Kawai, K. A new azaphilone, falconensin H, from Emericella falconensis. Chem. Pharm. Bull. 41, 2040-2041 (1993).
5 Itabashi, T., Ogasawara, N., Nozawa, K. \& Kawai, K. Isolation and structures of new azaphilone derivatives, falconensins E-G, from Emericella falconensis and absolute configurations of falconensins A-G. Chem. Pharm. Bull. 44, 2213-2217 (1996).

6 Arai, N. et al. Isochromophilones III VI, inhibitors of Acyl-CoA: cholesterol acyltransferase produced by Penicillium multicolor FO-3216. J. Antibiot. 48, 696-702 (1995) (Erratum: 48, C2 (1995)).

7 Natsume, M., Takahashi, Y. \& Marumo, S. Mitorubrinic acid, a morphogenic substance inducing chlamydospore-like cells, and its related new metabolite, (+)-mitorubrinic acid B, isolated from Penicillium funiculosum. Agric. Biol. Chem. 49, 2517-2519 (1985).

8 Pairet, L. et al. Azaphilones with endothelin receptor binding activity produced by Penicillium sclerotiorum: taxanomy, fermentation, isolation, structure elucidation and biological activity. J. Antibiot. 48, 913-923 (1995).

$9 \mathrm{Yu}$, B. Z. et al. Phomoeuphorbins A-D, azaphilones from the fungus Phomopsis euphorbiae. Phytochemistry 69, 2523-2526 (2008).

10 Phonkerd, N. et al. Bis-spiro-azaphilones and azaphilones from the fungi Chaetomium cochliodes VTh01 and C. cochliodes CTh05. Tetrahedron 64, 9636-9645 (2008).

11 Dong, J. et al. New nematicidal azaphilones from the aquatic fungus Pseudohalonectria adversaria YMF1.01019. FEMS Microbiol. Lett. 264, 65-69 (2006).

12 Quang, D. N., Stadler, M., Fournier, J., Tomita, A. \& Hashimoto, T. Cohaerins C-F, four azaphilones from the xylariaceous fungus Annulohypoxylon cohaerens. Tetrahedron 62, 6349-6354 (2006).

13 Tomoda, H. et al. Structure-specific inhibition of cholesteryl ester transfer protein by azaphilones. J. Antibiot. 52, 160-170 (1999).

14 Toki, S. et al. RP-1551s, a family of azaphilones produced by Penicillium sp., inhibit the binding of PDGF to the extracellular domain of its receptor. J. Antibiot. 52, 235-244 (1999).

15 Matsuzaki, K. et al. New brominated and halogen-less derivatives and structure-activity relationship of azaphilones inhibiting gp120-CD4 binding. J. Antibiot. 51, 1004-1011 (1998).

16 Fujimoto, H., Matsudo, T., Yamaguchi, A. \& Yamazaki, M. Two new fungal azaphilones from Talaromyces luteus, with monoamine oxidase inhibitory effect. Heterocycles $\mathbf{3 0}$, 607-616 (1990).

17 Nakamura, K., Kino, T., Niko, K., Kyotoo, S. \& Okuhara, M. Phospholipase A 2 inhibitors containing sclerotiorin from Penicillin sclerotiorum for treatment of inflammatory pancreatitis, and allergy JP 02255615 A2, 16 October (1990).

18 Quang, D. N. et al. Inhibition of nitric oxide production in RAW 264.7 cells by azaphilones from xylariaceous fungi. Biol Pharm Bull 29, 34-37 (2006).

19 Yasukawa, K. et al. Azaphilones inhibit tumor promotion by 12 -O-tetradecanoylphorbol-13-acetate in two-stage carcinogenesis in mice. Oncology 51, 108-112 (1994).

20 Quang, D. N., Hashimoto, T., Stadler, M. \& Asakawa, Y. Dimeric azaphilones from the xylariaceous ascomycete Hypoxylon rutilum. Tetrahedron 61, 8451-8455 (2005).

21 Yang, S. W. et al. A new hydrogenated azaphilone Sch 725680 from Aspergilus sp. J. Antibiot. 59, 720-723 (2006).

22 Yang, S. W. et al. Structure elucidation of a new antifungal sterol sulfate, Sch 575867 from a deep-water marine sponge (Family: Astroscleridae). J. Antibiot. 56, 186-189 (2003). 